\section{WHO WILL ENFORCE TOOTH WHITENING LAWS?}

How could the new tooth whitening legislation be used to make whitening safer for patients? This was the subject of debate at last month's meeting of the All-Party Parliamentary Group for Dentistry (APPGD) in Portcullis House, Westminster.

The law relating to tooth whitening changed on 31 October this year, clarifying that tooth whitening products with hydrogen peroxide levels greater than $0.1 \%$ should only be sold to and used by qualified dental practitioners. The attendees and members of the APPGD meeting generally welcomed the new law but questioned who would have the power to enforce it.

General Dental Council (GDC) illegal practice team solicitor Tessa Nejranowski confirmed that the GDC have received hundreds of complaints of complications from members of the public who had their teeth whitened by people without any dental expertise. Cases included chemical burns to the nose, mouth and cheeks in addition to resulting anxiety, burning sensations and altered tastes. However, Ms Nejranowski pointed out that her team 'cannot investigate and prosecute every case, often due to lack of evidence'. She claimed that the GDC are restricted by a lack of 'search and seizure' powers and having limited resources to prosecute those carrying out illegal whitening procedures. She called for more powers for the GDC and higher punishment for those convicted to advance the fight against those providing illegal whitening. Currently fines are limited to $£ 5,000$ in the magistrates' court.

Dr Stuart Johnson, Chair of the Council of European Dentists' working group on tooth whitening and a member of the British Dental Association's (BDA's) Principal Executive Committee, said that 'as professionals we should be using the lowest possible concentration [of hydrogen peroxide] to achieve the desired result'. Dr Johnson called on Trading Standards to use their powers to control the supply of whitening products to those carrying out illegal whitening.

In a statement released as the new legislation came into force, the British Dental Trade Association (BDTA) also called on Trading Standards to 'embolden their approach to tackling non-dentists who illegally provide tooth whitening' and called on the beauty industry to ensure that its members and those who train them understand the new legal framework.

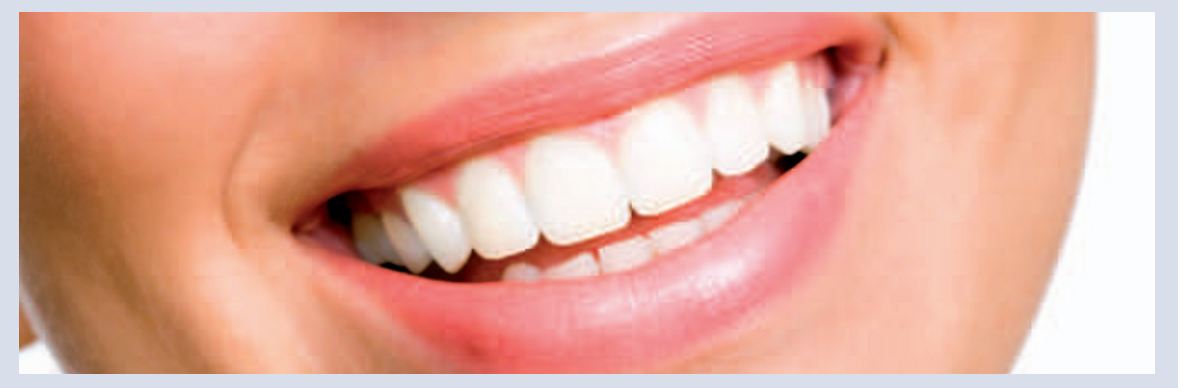

\title{
A FUSION OF CORE FUNCTIONS AND FREEBIES
}

How would a dental association be organised if it was invented today and not 100 years ago? That was the question which guided the development of the Dental Fusion Organisation, the new association which launched on 9 November. Its mission is to 'support and represent dental professionals working in primary dental care, improve oral health and provide social and clinical training for members'.
DFO will have no governing body; members will vote directly on every major issue through web and postal voting. If the members approve, one of the first campaigns will be to reverse the demise of the small independent family practice.

DFO Chief Executive Derek Watson said: 'In the age of the Internet, people are looking to source everything free of charge and yet they want an

\section{DENTAL ACADEMY TO LAUNCH IN SPRING}

Integrated Dental Holdings (IDH), a UK dental group with a network of over 500 practices, has announced the creation of a Dental Academy, providing leading edge clinical training for its dentists, which will launch in spring 2013.

The vision behind the Dental Academy is to deliver world-class training programmes initially for IDH staff, as part of IDH's commitment to the development of its people and the highest standards of dental care across the UK. Once established, The Academy will also open its doors to the wider profession and offer high quality development for non-IDH dentists.

The state-of-the-art facility and training centre will be based in Manchester, and include a fully functioning dental practice offering both NHS and private dentistry. The facility will have lecture rooms, seminar rooms and surgeries equipped to demonstrate treatments. This will include decontamination treatment facilities, radiography training facilities and a phantom-head room.

All forms of training are there to upskill dentists so they can provide more complex treatments and will also cover their general continuing professional development (CPD) as well as nurse, hygienist and therapist training. Both hands-on and web based teaching methods will be available.

Richard Smith, CEO at IDH, said: 'Dentistry is a rapidly changing industry in the UK, developments in preventive care and cosmetic solutions have increased the industry's need for an enhanced skill mix from dentists. [This] is our way of responding to the changing needs of our staff and customers.'

association that is very active, lobbies on their behalf and can give them advice when they need it. Dental Fusion has solved their problem by having its core functions funded by subscriptions, with over $£ 1,000$ of additional member benefits donated by suppliers using the "Freemium" model.'

Membership is open to all dental professionals and there is also a much tighter integration between the association and dental suppliers, hence 'fusion'. 